\title{
Experiential Learning: Music Industry Simulation as a Pedagogical Approach
}

\author{
Jerry Brindisi \\ Columbia College Chicago \\ This paper was presented at the 2019 International Summit of the \\ Music \& Entertainment Industry Educators Association \\ March 21-23, 2019
}

https://doi.org/10.25101/19.14

\section{Abstract}

Preparing students to work in the music industry has many challenges. Among them is providing opportunity to gaining experience and apply what they have learned in real world circumstance. Simulation exercises have been a method of training in a variety of industries since the early 1900 s. For educators attempting to offer students practical learning opportunities working on music industry scenarios and cases, simulation exercises or gaming can offer valuable experiences.

Simulation applied to management programs can provide students situations that tie multiple components of curricula together as building blocks for practical experiences. These experiences can be guided by faculty and allow students to navigate real world problems and dilemmas in a controlled environment. An exploration of simulation background is examined and an example of a current simulation game as a pedagogical approach to teaching music business is presented. Further inquiry into simulation and learning cycles is described and used to illustrate a method to assess learning outcomes of simulated experiences. An evaluation of student learning from assessment of simulation activities in course offerings provides some insight into the validity of this pedagogical approach and its usefulness in higher education.

This study builds on a previous co-published work titled "Implementing Game Pedagogy into Music Business Curriculum: The Music Industry Immersion" and provides a more detailed investigation of learning cycles and their connection to simulation as a development tool. Simulation assessment methods are introduced and a discussion of simulation feasibility are argued.

This paper will be of particular interest to music and entertainment industry instructors and program directors looking to incorporate "real-world" examples, alternative pedagogical approaches, and multimodal learning environments into curricula.
Keywords: experiential learning, simulation, gaming pedagogy, learning cycles, scenarios development, music business, learning outcomes, assessment, higher education, Columbia College Chicago, Jerry Brindisi

\section{Introduction}

Simulation exercises have been used in many industries since the early 1900s and studied significantly. The literature is extensive. As a learning tool and assessment tool a well-developed simulation can provide participants an accurate experience that mirrors professional practice. The focus of this paper is to consider assessment of a simulation exercise used within a music industry curriculum and how to capture the overall experience on students in a meaningful way. The development of simulated experiences is explored and a detailed example of a music business simulation exercise is presented. Additional considerations include emerging themes noted by participants and the broader impact on those involved are explored.

\section{What is Simulation?}

According to Dr. Richard Gran, member of the Apollo lunar module digital autopilot design team, "simulation is the creation of a model that can be manipulated logically to decide how the physical world works" (Gran 2012). This allows conclusions to be made and to answer questions in a way that may not otherwise be possible. Additionally, simulation is the construct of a model or process meant to emulate real-life scenarios.

They are useful in solving problems by testing theory without the commitment of a true active engagement and potentially unwanted results. Simulations are also a practical way for participants to train for professional practice. Simulations have been used extensively in science applications (control systems for example) and healthcare (role play) as well as for corporate training in order to model business functions (scenario based/number manipulation). 


\section{Why Use Simulations?}

There are a number of benefits to using simulated exercises in higher education. As a common practice in many fields simulations allow students a hands-on learning opportunity within a safe environment. In this way, "safe" meaning that the ramifications of participants actions within the simulation will not have undesired consequences but mainly serve as a learning opportunity.

Simulations have the potential to bridge theory and practice in a meaningful way for participants. Theories may be questioned, tested, and implemented. At the same time students may gain knowledge of theory and practice through their interactions with faculty and other participants in the simulation. Not only can students learn from their instructors but also from each other if given the opportunity within the simulation.

From a pedagogical perspective, students should be active participants making their participation more engaging and impactful as multiple learning styles can be accommodated. Shute and Glaser contend that simulations allow participants to learn concepts in less time (Shute 1989). Additionally, infrequently engaged skills can be honed by participants who may not otherwise have the opportunity to practice and develop these skills.

As an assessment tool, simulation can provide a robust opportunity to assess a participant's ability to successfully navigate an activity, scenario, and/or application of theoretical concepts, principles and practices. According to Quinn: "... any practice activity is inherently a performance opportunity and can serve as an assessment opportunity. In fact, the very contextualized practice, the close simulation of the actual performance situations, makes it a rich assessment tool, particularly compared to most knowledge assessments typically used (e.g., a test)" (Quinn 2007).

Fatimah Lateef argues a broad range of skills that can be developed using simulation including: technical and functional expertise training, problem-solving and decisionmaking skills, as well as interpersonal and communications skills or team-based competencies (Lateef 2010). This perspective ties simulation exercises to experiential learning.

As a pedagogical approach, simulation exercises may be a form of experiential learning. "In its simplest form, experiential learning means learning from experience or learning by doing. Experiential education first immerses learners in an experience and then encourages reflection about the experience to develop new skills, new attitudes, or new ways of thinking" (Lewis and Williams 1994).

A number of characteristics should be present in order to identify an activity as experiential. Chapman et al. have identified nine characteristics:
1. Mixture of content and process: There must be a balance between the experiential activities and the underlying content or theory.

2. Absence of excessive judgment: The instructor must create a safe space for students to work through their own process of self-discovery.

3. Engagement in purposeful endeavors: In experiential learning, the learner is the self-teacher, therefore there must be "meaning for the student in the learning." The learning activities must be personally relevant to the student.

4. Encouraging the big picture perspective: Experiential activities must allow the students to make connections between the learning they are doing and the world. Activities should build in students the ability to see relationships in complex systems and find a way to work within them.

5. The role of reflection: Students should be able to reflect on their own learning, bringing "the theory to life" and gaining insight into themselves and their interactions with the world.

6. Creating emotional investment: Students must be fully immersed in the experience, not merely doing what they feel is required of them. The "process needs to engage the learner to a point where what is being learned and experienced strikes a critical, central chord within the learner."

7. The re-examination of values: By working within a space that has been made safe for self- exploration, students can begin to analyze and even alter their own values.

8. The presence of meaningful relationships: One part of getting students to see their learning in the context of the whole world is to start by showing the relationships between "learner to self, learner to teacher, and learner to learning environment."

9. Learning outside one's perceived comfort zones: "Learning is enhanced when students are given the opportunity to operate outside of their own perceived comfort zones."

(As cited by Schwartz)

These characteristics set the stage for a model of development and assessment of simulation exercises in higher education. Considering these characteristics in development of simulation exercises may result in a more robust experience 
for participants. Additionally, using these characteristics to assess a simulation may provide insight into the validity of the simulation as an activity that truly reflects real-world experience.

\section{When Should Simulation Not Be Used?}

According to Prensky, “...it does not transfer particularly well to highly complex, highly indeterminate situations, such as economics, business, and human behavior." This statement is subject to criticism since simulation seems to be used effectively in a number of corporate training circumstances. It may refer however to the model of the simulation activity itself to be effective as its construct must take into account indeterminate situations as a key aspect of developing decision-making skills (Prensky 2002).

Cost and commitment are additional factors that must be considered in the decision to develop simulation-oriented curricula. Depending on the type of simulation created and the impact that it may have on participants, significant attention to the budgetary implications, time commitment of faculty and sheer amount if manpower must be explored. "Developing a simulation and getting students involved can be taxing, both on a professor's time and energy" (Strasser 2006).

\section{Simulation in Music Business Programs}

Simulation within music business curricula is not a new concept. Richard Strasser form Northeastern University published an article in the 2006 Edition of the MEIEA Journal (volume 6) titled "Simulation and Role Playing in Music Industry Education: An Assessment of the Effectiveness of an In-Class Simulation on Music Marketing Students' Perceptions and Learning Outcomes." This study is an analysis of multiple interconnected simulation exercises used in a music marketing and promotions course over a fifteen-week period. The findings of this study indicated a strong impact on learning and on meeting course objectives. It was noted that students were more active in the learning process than via using traditional evaluation methods, students had greater retention of material, but also it gave them what many consider to be lifelong skills beyond the area of marketing, such as time and organizational management and leadership skills (Strasser 2006). These findings are encouraging but the study also identifies its limitations and recognizes mixed research on simulation effectiveness.

The International Band and Business Camp or IBBC (formerly known as MuZone Partnership) is held annually in Germany and involves faculty members and students from institutions across Europe as well as Columbia College Chicago. This five-day camp includes a "Business Game" component involving music business students from partner institutions. This simulation runs students through an accelerated three years in seventy-two hours creating their own record labels, pitching investors, and navigating the experience in continued role-play scenarios that include business management and strategy, contract negotiations, marketing plan development, tour management, music publishing, sponsorship development, brand partnerships, and a number of other scenarios that develop organically during the development of each edition of the "game." The IBBC has taken place since 2005. Though its viability and commitment from partner institutions over this length of time is a testament to its effectiveness, formal student feedback forms have been limited to assessing only leadership/ collaboration skills, creativity/flexibility/problem solving skills, and knowledge/professional skills. Unfortunately records of this information have not been maintained.

\section{Developing A Simulation}

The design of a simulation and its use in practice is critical to its success as a pedagogical approach. A clearly defined purpose must be established before considering the development of a simulation. The developers must understand precisely what they what the participants to learn and experience in the simulation. As with any course and/or learning opportunity, clearly identified learning outcomes must be established and in alignment with the learning needs of the participants. The simulation must also be feasible. While an elaborate simulation exercise may be conceptualized, implementation may prove to be impractical and potentially offer students an experience that is unintended, unrealistic, and not useful as a learning opportunity. Simulations must be realistic and garner buy-in from the participants. The inventiveness of the simulation and the commitment to it by all participants, including the faculty is essential to its success.

Strasser suggests the use of grading strategies and nongrade strategies to improve involvement. Finally a simulation exercise should include a feedback loop that allows faculty members to gather information from participants and additionally allows participants to reflect on their own experiences. This idea of reflection in and of itself is a significant contributor to the learning process of a simulation exercise giving participants the opportunity to process the information they've received including new concepts as well as allowing them to consider a self assessment of their performance.

Simulation activities should be student-centered and take a constructivist approach to their design. According to Hoover, "Two important notions orbit around the simple idea of constructed knowledge. The first is that learners construct new understandings using what they already know. There is no tabula rasa on which new knowledge is etched. Rather, learners come to learning situations with knowledge gained from previous experience, and that prior knowledge 
influences what new or modified knowledge they will construct from new learning experiences. The second notion is that learning is active rather than passive. Learners confront their understanding in light of what they encounter in the new learning situation" (Hoover 1996).

A simulation should be constructed to mimic a system or practice. The instructor should develop scenarios to:

- allow students to apply knowledge and practice relevant skills

- $\quad$ analyze, identify issues, solve problems and formulate strategies

- learn by completed learning activities which resemble the real world challenges they are likely to face.

(Scivally, 2013)

The instructor sets parameters, rules, and assumptions to create a simulated environment. The environment or "world" created by the instructor is the "reality" students work within.

\section{Simulation and Assessment}

Simulation exercises have been used as an assessment tool in many fields. But what are the best ways to complete an assessment of learning that occurs via the simulation? According to Bray et al., "There is an urgent need to develop valid, reliable assessment instruments related to simulation-based learning" (2011). While the article focuses on pharmacy curricula, it identifies the fact that simulation assessment often focuses on pre- and post-simulation knowledge testing. This type of assessment is necessary to accurately determine what students are learning in addition to individualized learning that takes place in the periphery of the intended outcomes.

A good first step in considering simulation assessment is by exploring learning cycles. For the purpose of this article, the five learning cycles, or 5Es, developed by Bybee et al. are presented. The 5 Es as presented by Tanner include:

- Engage: sparks students' interest and gets them thinking about the desired concept or skill. Engagements can elicit students' prior knowledge about the subject and collect information on what students know, which can be used to guide instruction.

- Explore: students attempt to understand the material on their own or in groups. This phase can generate students' "need to know," and thus motivate them to find information on their own.

- Explain: students become more familiar with new ideas, terms, or ways thinking. The aim is not just for instructors to explain, but for students to explain (or display) their understanding of a concept.
- Elaborate: students apply what they have learned to novel problems or contexts. Students need to try out their new knowledge.

- Evaluate: students reflect on and demonstrate their understanding or mastery of concepts and skills, and instructors have opportunities to evaluate student progress toward achieving learning objectives.

(Tanner, 2010)

Using these learning cycles as test criteria to examine student experience during a simulation exercise can aid in the development of simulation scenarios to modify and adapt the environment and/or requirements of participants to better understand if learning objectives are being met while the simulation is occurring. Due to the comprehensive nature and form that a simulation may take, accurate assessment of learning during the simulation can be difficult. Building on the constructivist approach and the notions of Hoover presented here, individualized learning of students via simulation will likely vary. Assessment of these varied outcomes is essential to fully understand the impact and possibilities that a simulation activity may present.

The following section of this paper outlines the Music Business Workshop simulation experience launched at Columbia College Chicago. This excerpt was first published in College Music Symposium, Volume 56, 2016, "Implementing Game Pedagogy into Music Business Curriculum: The Music Industry Immersion," by Jerry Brindisi and Justin Sinkovich, and reprinted with permission of the authors.

\section{The Music Industry Immersion and The Music Business Workshop}

Inspired by the International Band and Business Camp offered by Popakademie University, Mannheim Germany and the MuZone Partners, the Music Industry Immersion (MII) is a set of three classes offered at Columbia College Chicago during the J-Term session (January session between fall and spring semesters). The MII includes three courses offered simultaneously: the Music Business Workshop, The Music Workshop, and The Recording Workshop. Columbia College's departments of Business and Entrepreneurship, Music and Audio Arts, and Acoustics offer these courses respectively. They are offered in the same timeframe to allow for collaboration of students across projects.

Students in the Music Workshop are formed into bands or ensembles to write original music and 
prepare an original performance of their music. The Audio Arts and Acoustics students record the original material and work with producers to create professional quality recordings and engineer a professional sounding live showcase of the music. Students in the Music Business Workshop are engaged in a simulation game of the music industry and are also required to prepare for the release of the original recordings created in addition to marketing and promoting the final live showcase. These courses are completed over five days with students meeting for twelve hours each day and earning three (3) credits for the course in which they are enrolled. For the purpose of this paper, the focus will be on the simulation portion of the Music Business Workshop (MBW), which takes place over 36 hours of the course.

\section{The Music Business Workshop Simulation Overview}

The MBW involves a situational simulation and includes role-playing to allow students to consider different options and make decisions (Lunce 2006). The simulation is a true collaborative experience with students attempting to reach common goals while sharing tools and activities (Leemkuil 2003).

For the simulation portion the Music Business Workshop, students are divided into teams that must prepare a plan to launch a new music business venture. All ventures must start out as some form of record company with a goal to sign artist to record deals and to release music in some form. Students are presented with an imaginary pool of money controlled by investors (faculty) for which they are competing. They must prepare a formal business plan that includes details of their proposed organization. This plan includes organizational structure, business activities, value proposition, target customer segments, sources of income, planned partnerships, explanation of costs, sources of revenue, and methods of distribution. This business plan is then presented to faculty who take on the role of investors listening to the prepared pitches of each team. This "kick-off" assignment or initial challenge allows students to begin working closely with their team and to establish the basis for which they will operate as a music business throughout the simulation. Students are free to create a business of their choice with only the constraint of initially functioning as a record company that must sign recording artists with whom they believe to be viable and that fit the strategy of their company. This caveat is a significant structure within the simulation, their company.

\section{Creating the Simulation Environment}

A base set of assumptions is introduced into the simulation to establish the environment within which the students and faculty will be working. These assumptions provide some constraints that help to frame the simulation for the students. For example, students are presented with established expenditures for items they will likely require to start and run their businesses. As an illustration, a common practice in the music industry is for companies to hire an independent promoter. For this reason the simulation assumptions include tiered costs for hiring an outside promoter based on the level and duration of service of the promoter. The students, however, must decide to use an outside promoter for their business activities and at what level. Additionally, students will have a clear understanding of the amounts of revenue they can generate from certain activities, such as the sale of a physical album. Because the scope of activities within the simulation may change and develop, new assumptions are often introduced by the faculty as activities progress.

To facilitate efficient transactions and increase the number of opportunities for students to learn, templates are used throughout the simulation for deal-making and reporting purposes. These provide further constraints for students. They will have access to a recording contract template, for example, in order to establish clear terms for the deal they will have to negotiate with a faculty member who will be in the role of an artist's manager. Other examples of templates used in the simulation are revenue reporting, accounting, and tour itineraries to name a few. Students are not limited to deals that exist within the provided templates. If students desire to engage in a business activity that will go beyond the scope of an existing template format, they will work with faculty to develop a new agreement or contract. This however will place the faculty member into the role of an attorney who will then charge the student a fee for his or her services. Because there are many transactional opportunities for students throughout the simulation and many 
are often repeated, students and faculty become aware of student learning and growth as the simulation progresses. It is not uncommon for a student company in the simulation to sign agreements for many artists which means they will have to negotiate the terms repeatedly. Of course, the objective is that hopefully they improve their position with each one.

The simulation is driven by two key components, the time clock and faculty engagement. The simulation timeframe within which students are working is accelerated. Every hour is a month during the simulation meaning every twelve hours is one year. This accelerated time adds stress and urgency and requires students to be conscious of their time when working, meeting deadlines, making appointments, and fulfilling contractual obligations. We will now turn our focus to the engagement of faculty.

\section{The Role of Faculty}

Faculty members in the Music Business Workshop perform a number of roles to engage students and to help guide them through the simulation. They initially function in the role of investors who will ultimately be majority shareholders of each company. They also take on roles as determined by the needs of the simulation as it progresses. For example, faculty members may be attorneys, artists, artist managers or a banker, sponsor, fan, producer, government official, etc. Faculty will also mentor each team and will regularly step out of their role within the simulation to guide students or answer questions. Because faculty members act within these different roles, students are made aware that they must confirm what role they may be assuming should it is not apparent. Also, students can ask to "speak with a faculty member" at any time if they need guidance.

Significant faculty engagement is required to establish and maintain progression in the simulation. A key task for faculty is to manage the simulation to ensure buy-in from the students, facilitate learning through feedback, promote continued engagement, and challenge students to be creative with their business endeavor. Working from a central office the faculty are also the ones who provide the students with evolving storylines and scenarios to present new challenges, force students to work out- side their comfort zone, and to create increasingly complex interaction. This is done primarily by presenting students with information that may or may not have an impact on the operation of their business. Students regularly receive information from faculty as shareholders, other persons, or business entities. To reward and challenge students and to facilitate progression through the simulation, information is passed on to them in forms identified by Kienda Hoji as good news, bad news, or dilemmas. They will then have to make decisions on the information presented and navigate to better their company's position (Hoji 2014).

In the Music Business Workshop faculty also produce an online publication called Pitchspork News where information is distributed about all companies' successes or failures, new opportunities, changes in industry environment, new assumptions, information about artists, or any news that may be useful to the student companies and progress within the simulation. In the most recent offering of this simulation class, one of the students who headed her team organization as CEO was fired by the majority shareholders for allowing the company to go an entire year without releasing any product. This meant that the company had zero revenue for the year. It was a very profound learning moment for the student and her team; one they will not likely forget, and one better learned in the classroom than out in the real world. Without all of the details of the situation, information about the firing was published in Pitchspork News. Once the tears from the experience dried, the student was quickly picked up by another student company and soon managed to find herself in a leadership role in that new company.

Student teams have regularly scheduled meetings with shareholders annually (or each day) to report their progress as a company and present the faculty shareholders with a plan for the upcoming year. This established a nice narrative for the students who can easily understand how their activities and engagement in the simulation connect and make sense as an experience for them. Additionally, at the end of the simulation, there is a reflection and debriefing (Leemkuil 2003) meeting with the faculty. 


\section{Motivating Students}

Extrinsic motivators such as status, access, and power are implemented throughout the Music Business Workshop. Students achieve status via the successes of their companies. These companies are often competing with others to sign recording agreements with particular artists perceived to be high profile within the simulation. A successful deal with one of these artists is a measure of status within the simulation. Faculty members also provide a daily leaderboard that ranks companies by a particular form of assessment. The criteria are not revealed to students until the leaderboard is posted. For example, a ranking might be for the most engaged company or the most music released within a simulation year. Access is represented by the relationships students develop through the course of the simulation with various entities within the simulation. As an example, students have the opportunity to build relationships with sponsor companies, booking agents, and just about any entity they can envision having a business opportunity for their company. Acting in these roles, faculty members have the ability to reward or allow these relationships to translate into positive results for the student companies or for individual players. Students have several opportunities to gain power within the simulation. Students take on different leadership roles within their organizations, will have access to important information they can leverage to increase their company's success, and can take actions that can result in increased revenue for their organizations.

Surprisingly, the grade that a student receives for their participation in the MBW seems to be of little importance to them as they progress through the simulation portion of the class. Students rarely bring up the question of a grade for performance during the simulation as they are extremely focused on the content of the simulation and are aware of the learning that is taking place.

\section{Learning Outcomes}

The Music Business Workshop provides students with the opportunity to learn to apply basic, intermediate, and advanced concepts previously learned in more traditional courses. Students examine music industry challenges and strategically develop solutions. Students plan and build a music business, and then implement a marketing campaign for hypothetical music releases and live performances.

Students are caused to react to unknown situations and improvise responses. Students practice leadership, innovation, and creativity through unforeseen challenges. The arts, entertainment, and media industries are rapidly evolving particularly due to technologies impact in content production, distribution, and communication. Succeeding as managers and entrepreneurs in these industries requires good leadership by properly managing the reaction of oneself, and empathetically reacting to opinions of others (Gleeson 2014).

The simulation portion of the Music Business Workshop provides opportunities for students to be challenged as leaders and team members. The simulation plunges students into a variety of situations that requires them to recall information they have learned, seek out unknown information, and react in a manner that will strategically better their position within the simulation. The use of their collective knowledge and experience along with the choices they make in applying that knowledge determines their success or failure. As an example, faculty will take on the role of artist management or attorney to negotiate a contractual agreement between the student company and an artist.

\section{Scenarios Contributing to Learning Outcomes}

The most common agreement in this simulation is a recording deal. Students will need to recall their knowledge of entertainment law, music publishing, and traditional terms of these types of agreements. They will need to consider the position of their company and the status of the artist with whom they are trying to enter into the agreement. The terms to which students agree will ultimately determine their success or failure in that venture. If they agree to pay the artist an advance of funds that cannot be recouped from music sales, they will realize a loss for their company. If they agree to a short-term agreement without appropriate options to renew, they could lose a successful artist or an artist in whom they have invested to another company. This new company may realize the benefits of the artist's development. Conversely, a strong agreement could result in a successful and profitable relationship with an artist. 
The simulation requires students to work closely in teams under intense conditions over long periods of time, which can sometimes be stressful and fatiguing. The pace at which they work, required decision making, and the competitive nature of the simulation provide students the opportunity to experience changes in their emotional state and gain an understanding of the ways in which they deal with pressure and fatigue. They also witness fellow students experience with these challenges and are often required to react to these situations. The manner in which students manage success, failure, and uncertain situations all becomes apparent in the course of the simulation.

\section{Music Business Workshop Assessment}

Assessment of learning outcomes involves a pre-simulation interview and review of students' coursework and industry experience as well as a post-simulation reflective argument paper assignment. The pre-simulation interview allows faculty to understand students' interests, abilities and needs as related to the content that will be covered.

Additionally, this interview allows faculty to initially place students within teams where individual's knowledge, experience, personalities, temperaments, and interests will complement one another. The post-simulation paper assignment gives students the opportunity to reflect on their experience and provide feedback to faculty indicating their perception of learning and meeting the simulation learning outcomes.

Assessment of learning takes place throughout the simulation in many forms. Students are required to complete/ sign record deals with artists as noted previously, develop marketing plans for music releases, and plan artist tours among other tasks they must navigate. Marketing plans are graded but rather than a letter grade students receive revenue back to their company within the simulation. A particularly strong marketing plan will result in profit for the company. A poor marketing plan would result in a loss of revenue, as budgets must be utilized when developing and implementing the plan within the simulation. Along with the revenue report provided students for each marketing plan submitted faculty give feedback and suggestions. This allows students to review and make improvements for subsequent marketing plans they develop. The repetition of similar assignments including this feedback loop promotes improvement and practical application as well as a means to assess student learning. A similar process is followed for tour planning.

\section{A Deeper Dive Into Assessment}

Understanding the varied broader impact this simulation has on individual students is a more challenging endeavor. Anecdotal feedback from students suggests a significant and powerful experience during the simulation. Comments such as "It changed my life" or "I've learned more in this class than any other class" are difficult to measure accurately from a learning assessment perspective. In an attempt to quantify the broader impact of this simulation on each student a comprehensive review of students' post-simulation assignments has been done to identify recurring learning themes. Themes identified include:

- Trusting Instincts

- Self Discovery

- Clarifying Miscommunication

- Using Knowledge/Materials from Previous Courses

- Adaptability

- Problem Solving

- Learning From Peers

- Delegating

- Inquiry

- Teamwork

- Time Management

- Resilience

- Attention to Detail

\section{Conclusion}

Having a better understanding of the wider affect of simulation experience on students is useful for the development of simulation exercises as well as offering a solution to achieve particular learning objectives educators may have for their students. The learning themes analysis for the music business workshop is a recent endeavor having only been implemented as an assessment model for the most recent offering of this simulation course. Continued analysis of learning themes as they emerge from continued offering of the Music Business Workshop will provide a statistically relevant sample size and a more reliable indication of the benefits of this simulated music business exercise. 


\section{References}

Bray, Brenda S., Catrina R. Schwartz, Peggy Soule Odegard, Dana P. Hammer, and Amy L. Seybert. "Assessment of Human Patient Simulation-based Learning." American Journal of Pharmaceutical Education 75, no. 10 (2011): Article 208. https://doi.org/10.5688/ ajpe 7510208 .

Bybee, Rodger W., Joseph A Taylor, April Gardner, et al. The BSCS 5E Instructional Model: Origins, Effectiveness, and Applications. Colorado Springs: BSCS Science Learning, 2006. http://www.fremonths.org/ ourpages/auto/2008/5/11/1210522036057/bscs5efullreport2006.pdf.

Chapman, Steve, Pam McPhee, and Bill Proudman. "What is Experiential Education?" In The Theory of Experiential Education, edited by Karen Warren, 235-248. Dubuque: Kendall/Hunt Publishing Company, 1995.

Gleeson, Brent, and Dyan Crace. "The Use of Emotional Intelligence for Effective Leadership." Forbes, December 29, 2014. http://www.forbes.com/sites/ brentgleeson/2014/12/29/the-use-of-emotional-intelligence-for-effective-leadership/.

Gran, Richard. "What is Simulation?" YouTube, December 19, 2012. https://www.youtube.com/watch?v=OCMafswcNkY, http://goo.gl/F3AiXp.

Hoji, Kienda. "Mu Zone The Documentary." YouTube, June 18, 2014. http://www.youtube.com/watch?v=YE4HgxcyKPk.

Hoover, Wesley A. "The Practice Implications of Constructivism." Southwest Educational Development Laboratory Letter 9, no. 3 (August 1996). http://www. sedl.org/pubs/sedletter/v09n03/practice.html.

Lateef, Fatimah. "Simulation-based learning: Just Like the Real Thing." Journal of Emergencies, Trauma and Shock 3, no. 4 (2010): 348-352. https://doi. org/10.4103/0974-2700.70743.

Leemkuil, Henny, Ton de Jong, Robert de Hoog, and Noor Christoph. "KM QUEST: A Collaborative Internet-based Simulation Game." Simulation \& Gaming 31, no. 1 (March 2003): 89-111. https://doi. org/10.1177/1046878102250605.

Lewis, Linda H., and Carol J. Williams. "Experiential Learning: Past and Present" In Experiential Learning: A New Approach, edited by Lewis Jackson and Rosemary S. Caffarella, 5-16. San Francisco: Jossey-Bass, 1994.

Lunce, Les M. "Simulations: Bringing the Benefits of Situated Learning to the Traditional Classroom." Journal of Applied Educational Technology 3, no. 1 (Spring/ Summer 2006): 38.
Prensky, Mark. "The Motivation of Gameplay." On the Horizon Volume 10, no. 1 (March 2002): 5-11. https:// doi.org/10.1108/10748120210431349.

Quinn, Clark. "Computer-Based Simulations: Principles of Engagement." In The Handbook of Experiential Learning, edited by Melvin L. Silberman, 138-154. Hoboken, New Jersey: Wiley, 2007.

Schwartz, Michelle. "Best Practices in Experiential Learning." ryerson.ca. Last Modified 2012. https://www. ryerson.ca/content/dam/learning-teaching/teaching-resources/teach-a-course/experiential-learning.pdf.

Scivally, Andrew. "8 Effective Scenario Ideas for Instructional Designers." Elearning Brothers. Last modified October 16, 2013. https://elearningbrothers.com/ blog/8-effective-scenario-ideas-for-instructional-designers/.

Shute, Valerie J., Robert Glaser, and Kalyani Raghavan. "Inference and Discovery in an Exploratory Laboratory." In Learning and Individual Differences: Advances in Theory and Research, edited by Phillip Lawrence Ackerman, Robert J. Sternberg, and Robert Glaser, 279-326. New York: W. H. Freeman, 1989.

Strasser, Richard. "Simulation and Role Playing in Music Industry Education: An Assessment of the Effectiveness of an In-Class Simulation on Music Marketing Students' Perceptions and Learning Outcomes." Journal of the Music and Entertainment Industry Educators Association 6, no. 1 (2006): 77-91. https://doi. org/10.25101/6.4.

Tanner, Kimberly D., "Order Matters: Using the 5E Model to Align Teaching with How People Learn." $C B E$ Life Sciences Education 9, no.3 (Fall 2010): 159-164. https://doi.org/10.1187/cbe.10-06-0082. 
Jerry Brindisi's passion for the music industry evolved from his great love of popular music. His interest and experience has progressed from a desire to perform, write songs, record, and ultimately create music product. Mr. Brindisi is an Associate Professor and Program Coordinator for the Music Business BA program at Columbia College Chicago. He oversees all music business courses offered by the Department and enjoys serving as a faculty advisor and mentor to music business students. He is currently serving as the Associate Chair of the Business and Entrepreneurship Department and is involved in program administration, curriculum development, teaching music business, and coordinating interdisciplinary ventures, including AEMMP Practicum courses (student run record label, artist management, music publishing).

Mr. Brindisi has an extensive background working in the music industry. He has been employed by Sony Music Entertainment Inc. as a Sales and Marketing Research Analyst in its Global Digital Business Group. He has also worked for the executive offices and the A\&R departments of Warner Music Group's Asylum Records and Atlantic Records. As the studio manager for Ander's Music, he has had the opportunity to work closely with top industry leaders, attorneys, artists, managers, producers, and songwriters. Additionally, Mr. Brindisi has advised and counseled music artists and industry executives on various industry issues including career advancement, publishing, marketing, promotion, and artist branding. His experience and research interests include record label operations, music publishing administration, audio production, and artist development. He previously served as a full-time faculty and program supervisor for the music business program at the State University of New York, Fredonia, where he taught courses such as Music Contracts, Music Copyright and Publishing, Music Marketing and Promotion, and The Business of Music.

Mr. Brindisi earned a Master's degree in Music Business from New York University where he was honored for outstanding scholarship, leadership, and service in the Graduate Music Business Program of the Steinhardt Department of Music and Performing Arts Professions. While attending NYU, he served as the assistant to the program director of Music Business. Mr. Brindisi holds a Bachelor's degree in Communication from SUNY at Buffalo with concentrations in public relations and advertising. Mr. Brindisi is a member of the Music and Entertainment Industry Educators Association (MEIEA) and is a recipient of the State University of New York Service to Students Award.

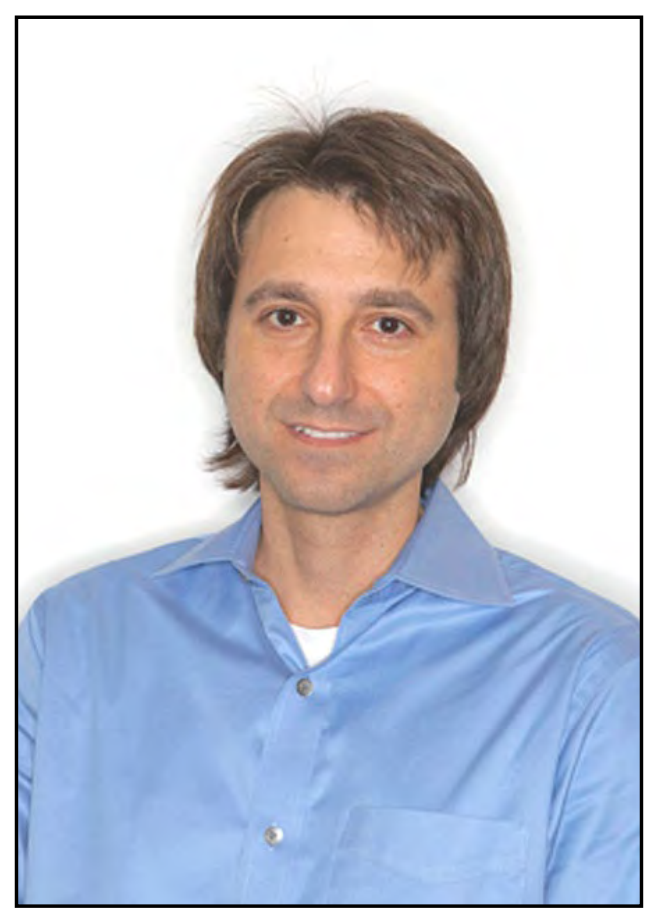




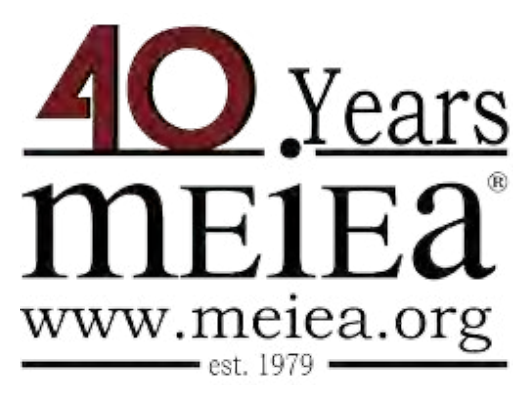

\section{PROCEEDINGS OF THE \\ 2019 INTERNATIONAL SUMMIT \\ OF THE \\ MUSIC \& ENTERTAINMENT \\ INDUSTRY EDUCATORS \\ ASSOCIATION}

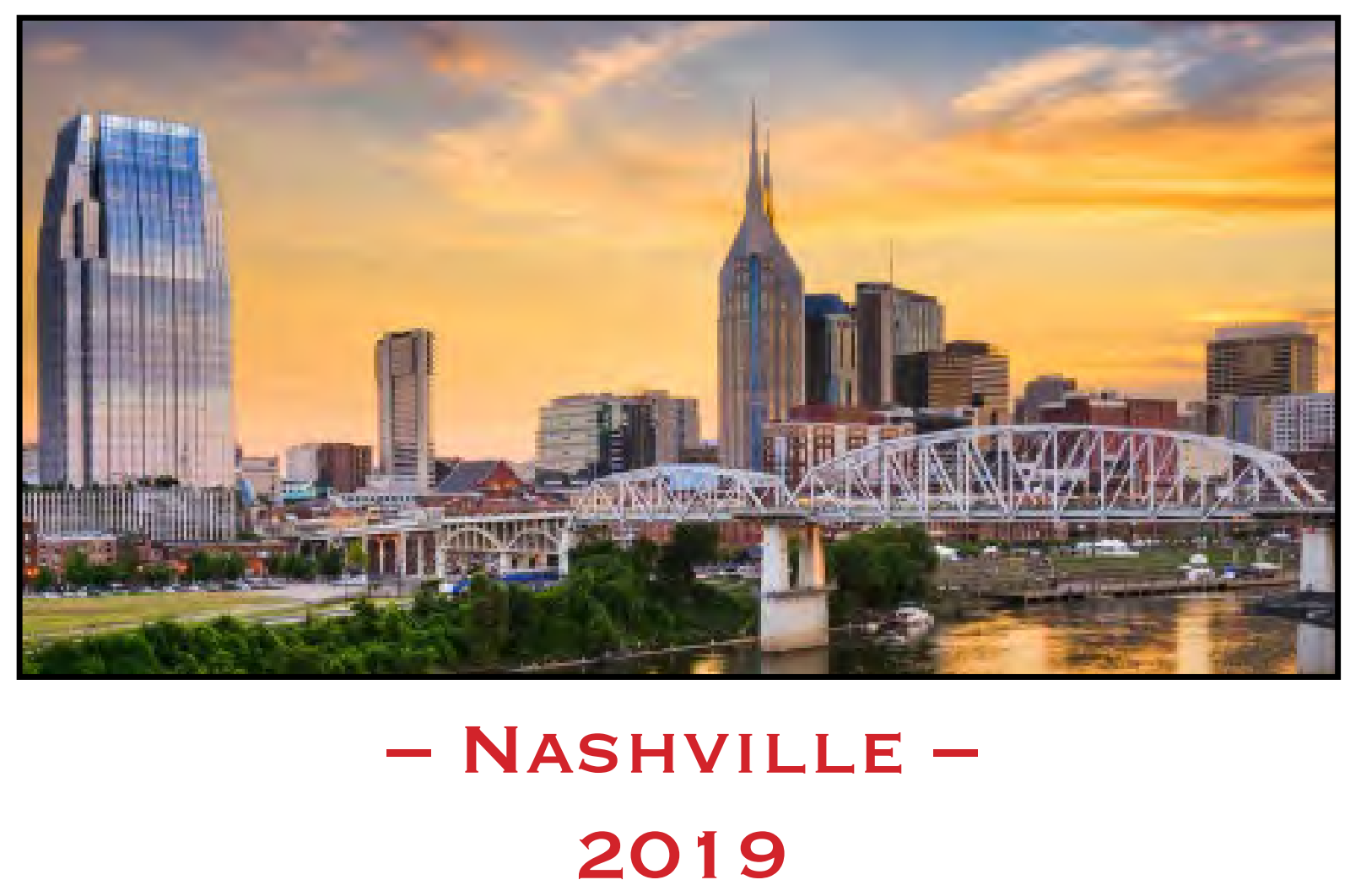

March 21 - 23, $2019 \cdot$ Belmont University - Nashville 